\title{
Hydatid Cyst of Tongue: A Diagnostic Challenge
}

\author{
Neeraj Aggarwal, ${ }^{1}$ Tanaya Panja, ${ }^{1}$ Khuku Biswas, ${ }^{1}$ Titas Kar ${ }^{1}$
}

Introduction

\section{$\underline{\text { ABSTRACT }}$}

Hydatid disease or human cystic echinococcosis is a parasitic zoonosis, endemic in the cattle and dog rearing region worldwide as well as in some parts of India.Cystic echinococcosis affects mostly the liver and lung (80\%), but tongue is one of the very rare sites.

Case Report

A 10 year old boy had presented with an isolated cystic lesion in tongue, which was expelled spontaneously with no residual lesion. On detailed examination, no other site in the body was involved.

$\underline{\text { Discussion }}$

Parasitic cyst of the tongue is rare entity. Microbiological and histopathological examination helped clinch the diagnosis Hydatid cyst should be considered as a differential diagnosis in isolated cystic lesion of tongue, especially in the risk group. $\underline{\text { Keywords }}$

Echinococcosis; Cysts; Tongue

$\mathrm{H}$ ydatid disease or human echinococcosis is a well-known parasitic zoonosis,endemic in the cattle and dog rearing region worldwide, mostly in the Mediterranean region, South America, Australia, Central Asia and East Africa. ${ }^{1}$ The incidence of hydatid cyst in India is 1-200 per 1,00,000 population; mostly in Kashmir, AndhraPradesh, Gujrat and Tamil Nadu. ${ }^{2}$ It occurs due to ingestion of gravid proglottids of Echinococcus granulosus. ${ }^{3}$

Dogs and other carnivores act as the definitive host where as cattle act as the intermediate host. Humans act as an accidental, intermediate and dead-end host. Hydatid disease is very rarely seen in the head and neck region. ${ }^{4}$ Here, we are presenting a case of hydatid cyst of tongue in a 10 year old child.

\section{Case Report}

A 10-year-old boy had presented in the

1 - Department of ENT, Medical College, Kolkata

\section{Corresponding author:}

Dr Neeraj Aggarwal

email: drneeraj5887@gmail.com
Otorhinolaryngology Outpatients Department with a tongue swelling, incidentally discovered 1-2 months back and gradually increasing in size, with history of contact with dogs and frequent tonguebite. The swelling was soft, cystic, non-tender, $2 \times 2 \mathrm{~cm}$ approximately, at the left lateral border of the anterior two-third of tongue with overlying normal tongue mucosa. The tongue movement was normal but a slight change in speech articulation was there. The differential diagnosis of mucous retention cyst, minor salivary gland tumour, epidermoidcyst, lymphangioma were made and Magnetic Resonance Imaging of tongue had been advised, but the patient did not follow-up.

The patient came after 1 month with pain and difficulty in swallowing for 2-3 days. The white cyst wall was exposed through a mucosal breach in the superior and lateral surface of tongue (Fig. 1A) and pulling the tongue laterally while examination caused more bulging. The patient was planned for surgical excision, but before it could be operated there was a sudden increase in pain and the cyst, as a whole, was expelled spontaneously (Fig. 1B). No remnant of the cyst was felt in the tongue mucosa. The cyst was round, $2 \mathrm{~cm}$ in diameter, white, with an area of bluish discolouration (Fig.1C). 


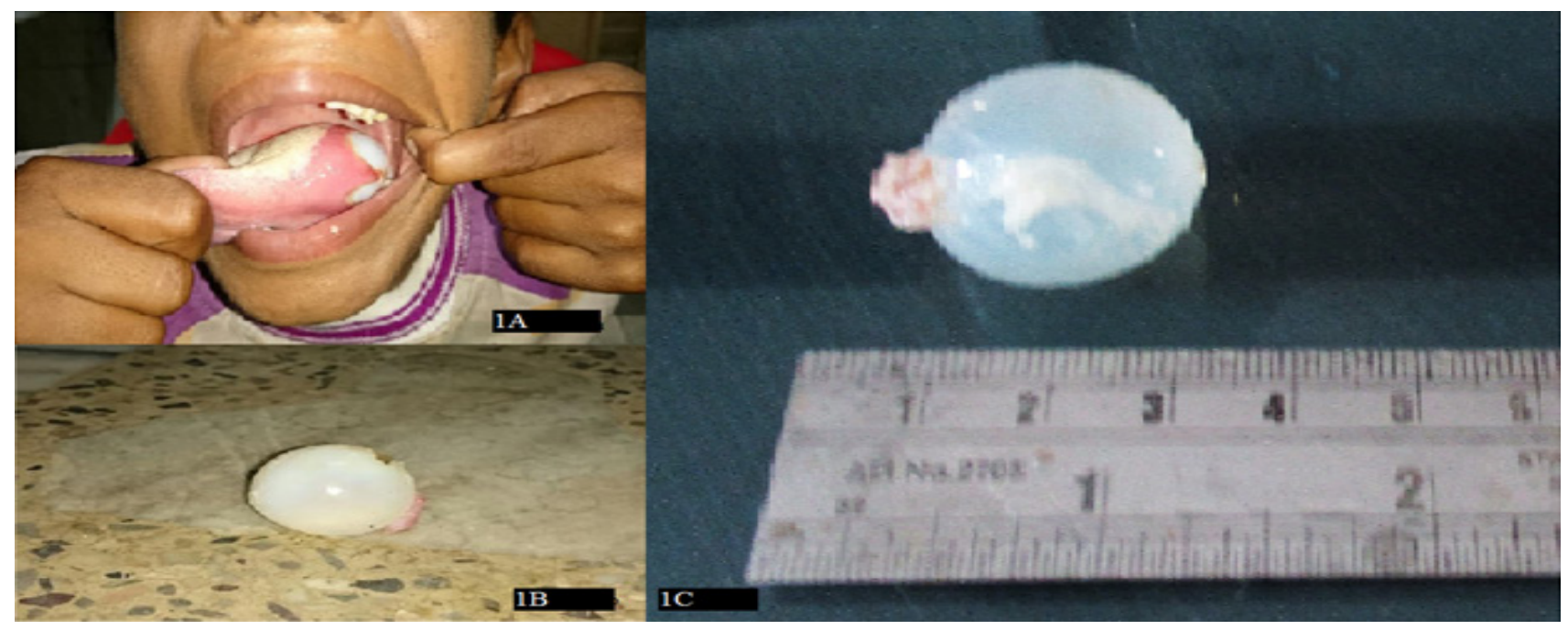

Fig. 1.A. The white cyst wall visible on protrusion of the tongue. $B$. The cyst after spontaneous expulsion. $C$. The close-up view of the cyst.

The watery fluid was aspirated (Fig. 2A), and sent for cytological, biochemical and microbiological analysis. In wet mount, invaginated scolex of Echinococcus was seen in Haematoxylin-Eosin stain (Fig. 2B).

The histopathology of cyst wall, in Periodic Acid Schiff stain, revealed outer hyaline and inner germinal layer. Both microbiological and histopathological reports confirmed the cyst to be a hydatid cyst.

Subsequent ultrasonography of neck and whole abdomen, chest X-ray and computed tomographic scan of brain failed to reveal any residual or disseminated disease. The tongue healed in approximately 14 days and there was no recurrence even after 6 months of follow-up.

\section{Discussion}

Hydatid disease, in human, affects mostly the liver and lung (80\%), but can be foundrarely in head and neck. ${ }^{4}$ The commonest cyst in oral cavity is mucous extravasation or retention cyst. Parasitic tongue cyst is quite unusual, cysticercosis caused by Taenia solium being the commonest. ${ }^{5}$ Tongue, as a location of hydatid cyst, is very rare. ${ }^{6}$ Only two cases of auto-expulsion of hydatid cyst of tongueare reported till date, both in India, in $1972^{7}$ and 2007. The present case is only the third reported case of auto-expulsion of tongue hydatid cyst, more unique in its isolated tongue involvement. The present case is only the third reported case of auto-expulsion of tongue hydatid cyst. West Bengal is not an endemic zone in India and the cyst, in location and appearance was no different from tongue mucous retention cyst. For this scenario hydatid cyst, as a differential diagnosis, was not considered initially. The suspicion came from the history of intimate contact of the child with dogs and cattle and its unique spontaneous expulsion. The diagnostic dilemma was overcome by a very simple technique of aspiration from the expelled cyst and the specific evidence of Echinococcus from the microbiological analysis.

The management plan prior to expulsion of the cyst was surgical excision under general anaesthesia. If the cyst ruptured during surgery, fatal anaphylactic reaction could have happened due to spillage of the hydatid cyst fluid over the buccal mucosa, upper respiratory tract and lung. ${ }^{8}$ The spontaneous expulsion itself could have been fatal,had the cyst ruptured during the process.

So, in isolated cystic lesion of tongue, hydatid disease should be considered as a differential diagnosis and during surgery, precautions should be undertaken to avoid rupture or spillage. Also the set-up for urgent general anaesthesia and supportivecare is needed even while performing surgery under local anaesthesia. In all cases of cystic tongue lesions, aspiration of cyst fluid 


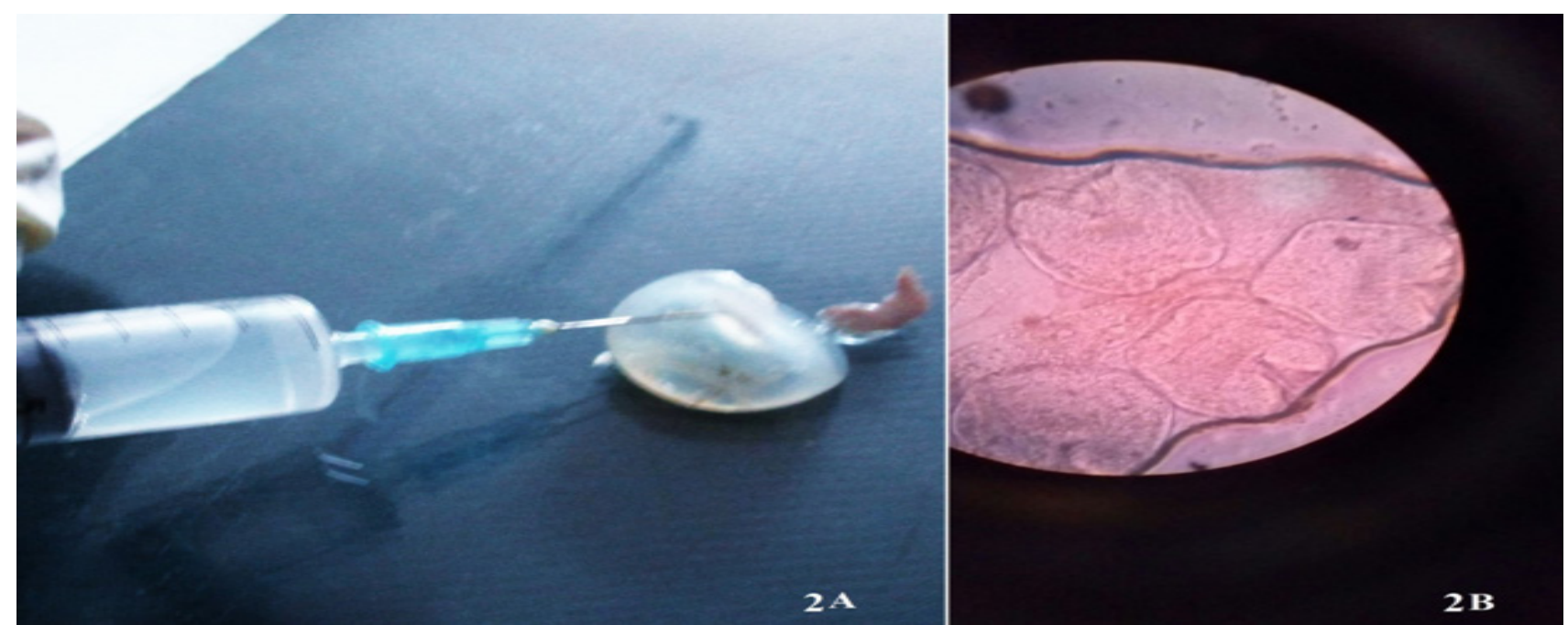

Fig. 2. A. Fluid being aspirated from the cyst. B. Invaginated scolex of Echinococcus (H\&E, 40X)

after surgical excision and its microbiological analysis is routinely recommended along with histopathology of cyst wall to exclude any parasitic cyst.

\section{References}

1. Rochidi Y, Raji A, Elhattab Y. A rare localization of hydatidosis: A cervical hydatid cyst. Fr ORL 2007; 92:315-7

2. Parikh F. Echinococcosis cut to cure but what about control? J Assoc Physicians India 2012; 60:9-10

3. Alaparthi RK, Yelamanchili S, Nunsavathu PN, Sode U. Intraoral hydatid cyst: A rare case report. J Indian Acad Oral Med Radiol. 2015; 27;457-60
4. Onerci M, Turan E, Ruacan S. Submandibular hydatid cyst (A case report). J Craniomaxillofacial Surg. 1991; 19:359-61

5. Khare P, Chauhan N, Dogra R, Kala P, Chand P. Isolated cysticercosis of tongue: A case report. Diagn Cytopathol. 2014; 42(8):716-8

6. Kirmani MA, Sajad M, Patigaroo AR, Khan AR. Hydatid cyst of tongue. JK Practitioner 2007; 14(2):107

7. Goel VP, Mehrotra TN, Bhatia BP, Gupta SN. Hydatid cyst of tongue (A case report). Journal of Indian Medical Association 1974; 63(1):28-30

8. Khurana S, Das A, Malla N. Increasing trends in sero prevalence of human hydatidosis in North India: A hospital-based study. Trop Doct. 2007;37;100-2. 